\title{
Sensibilização ambiental de estudantes da EJA de uma sala multisseriada no Projeto de Assentamento Porto Esperança em Confresa-MT
}

\author{
Elaine Darc Ramos ${ }^{1}$, Marcelo Franco Leão ${ }^{2}$ \\ 1,2 Instituto Federal de Mato Grosso - IFMT. Departamento de Ensino do Campus Confresa. Pós-Graduação em Ensino de \\ Ciências. Campus Confresa. Avenida Vilmar Fernandes, 300, Santa Luzia. Confresa - MT. Brasil. \\ Autor para correspondência/Author for correspondence: elainegraficamt2@gmail.com
}

\begin{abstract}
RESUMO. Esse estudo apresenta os resultados de uma intervenção pedagógica que visou promover sensibilização ambiental a estudantes de uma sala multisseriada da Educação de Jovens e Adultos (EJA) e discutir alternativas na busca pela sustentabilidade. Seu objetivo foi desenvolver reflexões, debates e ações que sensibilizassem esses estudantes sobre as questões ambientais e as práticas sustentáveis. Essa intervenção foi desenvolvida durante o ano de 2016 e envolveu uma sala com estudantes do $1^{\circ}$ e $2^{\circ}$ Ano do Ensino Médio da EJA. Uma particularidade dessa sala de extensão, é que a mesma é pertencente à Escola Estadual Waldir Bento da Costa, localizada no distrito de Veranópolis, município de Confresa-MT. Para tanto, foram realizadas pesquisas sobre o assunto, aulas de campo, palestra, leitura de textos e discussões em grupo para que fossem socializadas suas concepções sobre o tema e as práticas que vivenciam. Alguns instrumentos de coleta de dados foram os textos dissertativos que produziram, a observação participante e o registro no diário de bordo. Os estudantes demonstraram preocupação com o meio ambiente e que buscarão praticar ações sustentáveis em suas práticas cotidianas. Dessa maneira, é possível perceber que inserir a temática ambiental na EJA de uma escola do campo é uma necessidade e que essa formação mais êxito terá se estiver voltada para questões da vida cotidiana e para a relação equilibrada com o meio ambiente.
\end{abstract}

Palavras-chave: Educação Ambiental, EJA, Meio Ambiente, Sustentabilidade. 


\title{
Environmental awareness of EJA students from a multi- series room at the Porto Esperança Settlement Project in Confresa-MT
}

\begin{abstract}
This study presents the results of a pedagogical intervention aimed at promoting environmental awareness among students of a multi-tiered Youth and Adult Education (EJA) room and discuss alternatives in the quest for sustainability. Its objective was to develop reflections, debates and actions that sensitized these students on environmental issues and sustainable practices. This intervention was developed during the year 2016 and involved a room with students from the 1st and 2nd year of EJA High School. One peculiarity of this extension room is that it is owned by Waldir Bento da Costa State School, located in the district of Veranópolis, municipality of Confresa-MT. For that, research was done on the subject, field classes, lecture, reading of texts and group discussions in order to socialize their conceptions about the theme and the practices they experience. Some instruments of data collection were the essay texts that produced, the participant observation and the logbook record. Students have shown concern for the environment and will seek to practice sustainable actions in their daily practices. In this way, it is possible to perceive that inserting the environmental theme in the EJA of a rural school is a necessity and that this training will be more successful if it is focused on issues of everyday life and the balanced relationship with the environment.
\end{abstract}

Keywords: Environmental Education, EJA, Environment, Sustainability. 


\section{Sensibilización ambiental de estudiantes de la EJA de una sala multiserial en el Proyecto de Asentamiento Porto Esperança en Confresa-MT}

RESUMEN. Este estudio presenta los resultados de una intervención pedagógica que pretendía promover sensibilización ambiental a estudiantes de una sala multiserial de Educación de Jóvenes y Adultos (EJA) y discutir alternativas en la búsqueda de la sostenibilidad. Su objetivo fue desarrollar reflexiones, debates y acciones que sensibilizara a esos estudiantes sobre las cuestiones ambientales y las prácticas sostenibles. Esta intervención fue desarrollada durante el año 2016 e involucró una sala con estudiantes del $1^{\circ}$ y $2^{\circ}$ Año de la Enseñanza Media de la EJA. Una particularidad de esa sala de extensión, es que la misma es perteneciente a la Escuela Estadual Waldir Bento da Costa, ubicada en el distrito de Veranópolis, municipio de Confresa-MT. Para ello, se realizaron investigaciones sobre el tema, clases de campo, charla, lectura de textos y discusiones en grupo, a fin de que fueran socializadas sus concepciones sobre el tema y las prácticas que vivencian. Algunos instrumentos de recolección de datos fueron los textos disertivos que produjeron, la observación participante y el registro en el cuaderno diario. Los estudiantes demostraron preocupación con el medio ambiente y que buscarán practicar acciones sostenibles en sus prácticas cotidianas. De esta manera, es posible percibir que insertar la temática ambiental en la EJA de una escuela del campo es una necesidad y que esa formación más exitosa se habrá orientado hacia cuestiones de la vida cotidiana y para la relación equilibrada con el medio ambiente.

Palabras clave: Educación Ambiental, EJA, Medio Ambiente, Sostenibilidad. 


\section{Introdução}

$\mathrm{Na}$ educação contemporânea, assuntos referentes à Educação Ambiental (EA) e a sustentabilidade são cada vez mais recorrentes. Entre os temas geradores mais explorados em sala de aula são aqueles que visam à melhoria da qualidade de vida, os ecossistemas ameaçados pela ação do homem, a exploração de recursos naturais, a demanda de consumo e os hábitos adotados pela atual sociedade capitalista.

Nesse sentido, promover a EA por meio de práticas pedagógicas é uma necessidade, pois somente quando a população estiver sensibilizada haverá a percepção da necessidade de uma relação mais equilibrada com a natureza (Brasil, 2012). Além disso, é preciso considerar que grande parte das escolas adota um ensino voltado a essa sensibilização, ou seja, que se preocupa com o educar a fim de garantir formas de vida e de consumo com sustentabilidade para as futuras gerações.

Outra característica a ser considerada é que em escolas do campo, especialmente as que atendem a Educação de Jovens e Adultos (EJA), é indicado trabalhar a EA de maneira interdisciplinar, o que resulta, muitas vezes, no desenvolvimento de projetos de intervenção, unindo diversas disciplinas entorno de um mesmo objetivo.
Em seus estudos, Sato (2004) afirma que este entendimento sobre projetos de intervenção, atribui-se a utilização de temas geradores que promovem a interdisciplinaridade.

Em seus estudos, Andreola (2000) defende que os temas geradores podem ser considerados como bons paradigmas interdisciplinares a fim de desenvolver pesquisas na escola. Essas ações educativas favorecem a integração dos diferentes campos do conhecimento científico, além de auxiliarem na organização curricular adotada pelo professor.

Nessa mesma linha de pensamento, é preciso que os espaços escolares se apropriem de didáticas que proporcionem aprendizados para a vida dos indivíduos, que os tornem capazes de interagir com o meio e com as pessoas de maneira harmoniosa na tentativa de construir consciência crítica. Assim, compete a escola promover ações reflexiva para a construção de argumentação do senso comum ao mesmo tempo de ser capaz de conduzir os processos de ensino e de aprendizagem sem retirar a autonomia dos sujeitos.

Outra característica a ser considerada, segundo Melo e Rotta (2010), é que a escola é o local por excelência em 
que os estudantes têm seus primeiros contatos com os conhecimentos científicos, com as soluções da ciência para os problemas da vida. Nesse espaço é preciso ocorrer o estabelecimento de ligações entre os saberes científicos, que mediados pelo professor se tornam em saberes escolares, e a resolução de problemas em situações reais (Andreola, 2000).

O presente estudo aborda um assunto importante para a vida que é a sustentabilidade ambiental. Ao utilizar essa vertente da EA como tema gerador das aulas na EJA, esperou-se que as discussões e aprendizados fossem construídos em sala de aula. Essa intervenção pedagógica ocorreu em uma escola do meio rural, distrito de Veranópolis, município de Confresa/MT, durante o ano letivo de 2016.

Uma motivação por essa escolha é o próprio espaço escolar, por ser uma instituição localizada na área rural que também precisa de cuidados com a natureza. Foi então planejado um trabalho educativo integrado e interdisciplinar, o qual buscou estabelecer relações entre os conhecimentos de biologia, geografia, artes e língua portuguesa em sala de aula, tudo visando promover sensibilização quanto à sustentabilidade ambiental desses estudantes da EJA.
Conforme Santos e Leão (2017), o cenário encontrado em grande parte das escolas do campo não é nem um pouco favorável ao desenvolvimento de ações inovadoras em laboratórios de ciências ou de informática, ou seja, os autores apontam que existem dificuldades que precisam ser superadas pelos professores das escolas do campo. Essa constatação se conforma das escolas do campo da região e se ampliam em salas de extensão, cujo acesso ainda é mais difícil. Por isso que as experiências pedagógicas indicadas para esse contexto precisam envolver e explorar a própria realidade para poder compreendê-la e transformá-la quando necessário.

Nesse sentido, o estudo teve como objetivo desenvolver reflexões, debates e ações de sensibilização sobre as questões ambientais a estudantes de uma sala multisseriada da EJA e discutir alternativas que promovam a sustentabilidade ambiental como um exercício da cidadania.

A sensibilização pretendida pelo estudo é no sentido de que a educação busque sempre em suas atividades pedagógicas a reflexão dessas temáticas transversais para que essa formação humana prepare de fato os estudantes da EJA para saber agir em situações diárias, não apenas para o mercado de trabalho, mas sim frente aos dilemas que enfrentarem em suas vidas. 


\section{Discursos teóricos sobre a Educação de Jovens e Adultos}

O direito à educação é uma conquista universal estendida a todas as pessoas, cuja defesa dessa extensão aos jovens e adultos foi melhor delineada pelas conclusões da V Conferência Internacional de Educação de Adultos, realizada em 1997, na cidade de Hamburgo na Alemanha (Unesco, 2004).

Esse direito à educação para jovens e adultos no Brasil, foi assegurado inicialmente na Constituição Federal (Brasil, 1988), que declarou ser a educação o meio para o exercício da cidadania e, por isso, um direito universal. No entanto, a EJA se firmou como política pública e modalidade de ensino a partir da Lei de Diretrizes e Bases da Educação Nacional $\left(\right.$ LDBEN) $\quad \mathrm{n}^{\text {o }} \quad 9394 / 96$ e $\quad$ a $\quad$ Lei Complementar $\mathrm{N}^{\circ} 49 / 98$, que atribui ao Estado o dever de oferta educação a todos, inclusive aos que não tiveram acesso na idade própria, respeitando suas especificidades, histórias de vida e trajetórias (Brasil, 1996).

Entende-se então, que o reconhecimento da EJA como direito público subjetivo, a oferta gratuita, particularmente nessa modalidade, vem se consolidar no processo de democratização no país, garantindo também a dignidade e o resgate da cidadania a essa população que sempre se viu excluída.

A EJA se concentra em resgatar indivíduos, que por alguma razão não concluíram seus estudos na idade própria. Se caracteriza em formar grupos heterogêneos, tanto do ponto de vista das idades, das visões de mundos, da cultura e da bagagem de conhecimento prévios. De acordo com o Caderno Trabalhando com a Educação de Jovens e Adultos (Brasil, 2006, p. 8):

É na escola que esses alunos
encontram um espaço de recolocação
social, de desenvolvimento social e
autoestima. É nesse sentido que os
alunos da EJA diferem dos demais
grupos de estudantes, como por
exemplo, as crianças ou os
adolescentes. Esses grupos de jovens
e adultos precisam enxergar a escola
como um lugar que poderá suprir
suas necessidades como pessoa,
cidadão e como um aprendiz em
potencial.

Partindo dessa premissa, ao e terem o contato com professores e o espaço de sala de aula, despertam em si motivação e interesse para a aprendizagem. Dessa forma, o ensino de ciências para sustentabilidade atribui-se a troca de experiência que ambos possuem e suas experiências já vivenciadas.

Nessa modalidade de ensino, os jovens e adultos precisam ser potencializados em suas habilidades individuais, até mesmo como forma de 
suprir as carências causadas pelo processo de exclusão histórica a que foram submetidos. Em outras palavras, é preciso conhecer e compreender os estudantes da EJA para então organizar as atividades pedagógicas. Neste sentido, é relevante o professor considerar a dinâmica e especificidades da EJA, tão enfatizada por Arroyo (2006).

Nessa mesma linha de pensamento, Soares (2008) sugere a necessidade de os professores conhecerem de maneira aprofundada o perfil desses estudantes. Segundo as palavras do autor, para que o professor consiga delinear esse perfil:

... é preciso considerar a realidade em que o aluno está inserido, como ponto de partida das ações pedagógicas, o currículo com metodologias e materiais didáticos adequados às necessidades, $\mathrm{o}$ financiamento para a concretização de ações e, finalmente, a formação de professores condizente com as especificidades da EJA. (Soares, 2008, p. 57).

Segundo estudos de Leão (2014), os estudantes da EJA são indivíduos abertos à aprendizagem, ou seja, apresentam prédisposição em aprender e a recuperar o tempo que não puderam estudar. Além disso, é indicado para essa modalidade de ensino que sejam desenvolvidas ações para interligar os sujeitos, que levem em consideração a formação de indivíduos mais críticos e sensíveis em relação às questões do meio ambiente.

Também é preciso considerar que os estudantes da EJA trazem uma noção de mundo mais relacionada ao ver e ao fazer, visão que vem apoiada a uma adesão espontânea e imediata às coisas que observam e praticam no cotidiano.

Não podemos esquecer que uma das funções da EJA, sendo uma modalidade de ensino que objetiva a transformação social e a formação humana, facilitando a aproximação da sociedade com a ciência (Brasil, 2006). Assim, no momento em que o professor trabalha com estratégias pedagógicas diversificadas em suas aulas, além de favorecer o processo educacional, é possível verificar mudanças de atitudes nos estudantes, ou seja, o desenvolvimento cognitivo e humanístico é impulsionado e dessa foram exercitam a cidadania.

Diante da reflexão supracitada, percebe-se que há possibilidade de iniciar, por meio da proposta da EJA, o enfrentamento a esse desafio ao se provocar $r$ a diferença em sala de aula, tanto no entendimento ao perfil do trabalhador estudante, quanto ao do professor no exercício da prática docente. Dentro desse contexto, o desenvolvimento de projetos educacionais que discutem temas geradores potencialmente 
significativos para os estudantes, é uma alternativa viável para a EJA.

De acordo com Arroyo (2006), o desenvolvimento de projetos requer uma visão de que se deve partir de um ponto de vista do qual os estudantes da EJA sejam capazes de fazerem os julgamentos dos prós e contras das situações problemas que serão trabalhadas em sala de aula no decorrer de seus cursos. Sendo assim, a realização de atividades de pesquisa, reflexão, debate e sensibilização proporcionados pelo desenvolvimento de projetos educativos, favorece que os estudantes da EJA se posicionem de maneira crítica e autônoma frente às situações reais em suas vidas.

\section{Reflexões sobre a importância da Educação Ambiental}

Devido à aceleração das transformações ambientais que nosso planeta está sofrendo para atender as demandas da sociedade do consumo, a escola precisa orientar seus estudantes sobre os cuidados que precisamos ter com o ambiente em que vivem. Os professores precisam desenvolver ações que possam orientar e sensibilizar para que possam se posicionar de maneira consciente frente às situações de responsabilidade socioambiental.
De acordo com a Resolução $\mathrm{N}^{\circ}$ 02/2012, que estabelece as Diretrizes Curriculares Nacionais para a Educação Ambiental, um dos objetivos da EA nas escolas é proporcionar aos estudantes a compreensão das relações existentes entre meio ambiente e as práticas sociais, no intuito de fomentar novos hábitos referente a produção e ao consumo (Brasil, 2012).

Nesse sentido, a EA tem como objetivo enfatizar a importância de ações combinadas para assegurar que os padrões do desenvolvimento que favoreça e ofereça a qualidade de vida para todos. Assim, a sensibilização sobre a importância da sustentabilidade ambiental é fundamental para promover ações que priorizam o desenvolvimento sustentável e uma melhoria na capacidade das pessoas em entender os problemas do meio ambiente e do desenvolvimento.

As discussões entorno da Política Nacional de Educação Ambiental, apontam que a EA não deve ser vinculada a uma disciplina do currículo escolar, mas que ocorra de maneira transversal, por meio de atividades que incorporem as temáticas ao processo educativo (Brasil, 2012). As diretrizes orientam que essas ações ocorram de maneira a promover a integração de saberes que busquem adquirir umas práxis crítica e reflexiva para uma formação cidadã. 
Segundo Freire (2001), para conhecer os temas geradores a serem trabalhados em sala de aula, é necessário partir do entendimento do todo, ou seja, só se tem uma ideia das situações conflitivas quando se tem uma visão de totalidade do contexto. Assim, segundo o autor, os temas geradores existem nos homens, em suas relações com o mundo, para tanto a proposta parte do estudo da realidade que é a fala do estudante, e a organização do dado que é a fala do professor.

O educador supracitado entende que é preciso priorizar os saberes dos estudantes que são permeados por suas experiências. $\mathrm{O}$ autor acredita que, por meio de reflexões e sensibilização, o homem vai se descobrindo, e ao descobrir a si próprio, ele mesmo irá se interrogar e buscar respostas às suas necessidades, questionamentos e anseios, sempre se posicionando influenciado por suas experiências de vida.

Por isso, o presente estudo se propõe a sensibilizar os estudantes em relação a suas ações no meio ambiente ao qual estão inseridos. Acredita-se que a prática adotada por essas pessoas no futuro será o reflexo das experiências oportunizadas pela escola, bem como na sociedade em que vivem. Além do mais, é um dos objetivos da EA esse processo de formação humana holística e que parte da própria realidade (Brasil, 2012).

Segundo as palavras de Freire (2001, p. 77):

O homem é capaz de realizar uma série de atividades complexas de forma simultânea, além de transformar o mundo com suas ações e captar e expressar a realidade por meio da linguagem. Isso o faz peculiar e diferente de outros animais presentes na Terra e, ao mesmo tempo, se faz com o mundo, e não está reduzido a um puro estar no mundo; logo, existe ... O homem ainda é capaz de questionar e refletir sobre a sua existência e suas relações com o mundo.

Em outras palavras, o autor supracitado evidencia que a relação das pessoas com o mundo independe do seu estágio de desenvolvimento cognitivo ou biológico. Em seu entendimento, não importa ser criança, jovem, adulto ou idoso, ser alfabetizado ou analfabeto, todos são capazes de realizar suas leituras de mundo e atribuir significados que lhes sejam pertinentes. Outra característica levantada pelo autor é que a criticidade e a autonomia são capazes de integrar o sujeito ao meio, ou seja, são habilidades necessárias para transformar a realidade.

Os estudos de Sauvé (2005) refletem sobre os benefícios e necessidade de discutir a problemática ambiental em sala de aula, sobre os diferentes saberes envolvidos entorno desse tema, sobre a 
importância de proporcionar o diálogo e a aproximação entre os diferentes conhecimentos, sejam eles científicos ou de senso comum, dos cotidianos e os oriundos da experiência. Compreender as relações entre o ambiente e o consumo, entre o que causa problemas e o que traz benefícios para a vida, auxilia na constituição de valores a serem assumidos que serão determinantes em suas atitudes e comportamentos.

Esses valores relacionados ao meio ambiente, segundo Leff (2000), são desenvolvidos de diversas formas, mas geralmente motivados pelos princípios da ecologia, pelos direitos comuns e universais, ou ainda pelos interesses das sociedades. $\mathrm{O}$ autor ainda sugere que as ações da EA considerem a perspectiva da complexidade, pois estamos envolvidos por elementos correlacionados e interligados e essa compreensão é que permitirá enxergar e respeitar o mundo e os papéis de cada agente nele presente.

$\mathrm{O}$ entendimento sobre $\mathrm{o}$ ato educativo pretendido vem ao encontro do que defende Freire (2005): educar é um ato político! Nesse sentido, a proposta dessa intervenção pedagógica em abordar a sustentabilidade ambiental é no intuito de ir além daqueles valores ligados à conservação da natureza, pois é preciso muito mais. A sensibilização proposta visa à construção de uma postura crítica e autônoma diante de situações problemas que ocorrerem no cotidiano desses estudantes.

\section{Procedimentos metodológicos}

O presente estudo se caracteriza como uma pesquisa descritiva e exploratória, cuja abordagem é qualitativa. Trata-se de uma intervenção pedagógica, desenvolvida durante o ano de 2016, e teve por finalidade desenvolver ações interdisciplinares visando a sustentabilidade ambiental.

A abordagem qualitativa, segundo Gil (2010), é aquela que permite compreender de maneira subjetiva um fenômeno ou objeto escolhido para investigação. Os procedimentos adotados foram similares aos indicados por Leff (2000), que defende abordar questões da EA considerando o contexto e a complexidade.

O lócus da pesquisa foi a Escola Estadual Waldir Bento da Costa (sala de extensão José Anísio do Projeto de Assentamento Porto Esperança), localizada na área rural, no distrito de Veranópolis, município de Confresa-MT. A escola funciona nos turnos matutino e noturno. Essa instituição educativa é considerada como uma escola do campo, e oferta Educação Fundamental e Ensino Médio 
nas modalidades regular e EJA. Seu público é constituído por pessoas bastante diversificadas, pois todos os estudantes residem ou moram no meio rural. Por ser a única escola situada no distrito, acaba atendendo todo o público local.

Como participantes da pesquisa, foram envolvidos 31 estudantes do $1^{\circ}$ e $2^{\circ}$ Ano do Ensino Médio da EJA dessa escola. Cabe aqui registrar que essa sala é multisseriada, ou seja, mesmo sendo de etapas de escolarização diferentes, esses estudantes estudam na mesma sala.

A intervenção pedagógica escolheu como tema gerador a sustentabilidade ambiental. Alguns dos procedimentos metodológicos e estratégias adotadas foram: aula expositiva dialogada e participativa, aulas de campo, pesquisas sobre o assunto, leitura de textos e discussões em grupo afim de que fossem socializadas suas concepções sobre o tema e as práticas que vivenciam, produção de textos e produção de fotos pelos estudantes sobre a sustentabilidade ambiental. Também foram realizadas palestras sobre a temática.

A produção de textos foi uma das atividades propostas que serviu para diagnosticar o que pensam sobre sustentabilidade e como estabelecem suas relações com o meio ambiente. Essa ação foi muito importante, pois trabalhar com a temática ambiental requer primeiramente conhecer a realidade desses estudantes para traçar as metas necessárias na busca por uma relação equilibrada entre homem e natureza.

Para proceder com esses estudos, foi proposta a realização de uma pesquisa sobre "sustentabilidade e meio ambiente", com a intenção de socializar os estudos e preocupações sobre o assunto. A intenção foi envolver também os conhecimentos prévios de maneira que esses estudantes pudessem expressar o que já compreendiam sobre o processo. Desse modo, o ponto de partida foram as concepções sobre o assunto em estudo, para somente após serem realizados os estudos teóricos por meio de pesquisas e leitura na internet, sites, revistas, jornais e livros.

Outra atividade desenvolvida foi a palestra intitulada "Manejo e qualidade do leite e a conservação das matas e áreas de florestas" que foi ministrada pelo médico veterinário Sr. Ralf Bitencurt. Em outra ocasião também ocorreu a palestra "Saúde e meio ambiente", ministrada pelo agente de saúde dessa localidade (Projeto de Assentamento Porto Esperança). Essas atividades aconteceram de forma aberta para a participação dos moradores locais. $\mathrm{Na}$ ocasião os estudantes foram motivados a convidar seus familiares e vizinhos para 
prestigiar as palestras. Essas ações permitiram levar informações que contribuíram para o entendimento da comunidade escolar local sobre desenvolvimento sustentável.

Uma última ação proposta foi a produção fotográfica dos estudantes que permitiu identificar soluções socioambientais geradas pelas ações educacionais desenvolvidas em aula. A intenção da ação foi proporcionar que os estudantes buscassem a campo, por meio da análise de seus próprios domicílios, o estabelecimento de relações com aquilo que estavam estudando em sala de aula. A autorreflexão de suas práticas cotidianas unidas às informações recebidas na escola pode contribuir com suas ações diárias no sentido de buscar práticas sustentáveis.

Serviram como instrumentos de coleta de dados os textos dissertativos produzidos pelos estudantes, a produção fotográfica de aspectos locais, a observação participante da professora pesquisadora e o registro das atividades desenvolvidas no diário de bordo. Anexo a esse artigo, são apresentadas algumas produções textuais sobre as atividades desenvolvidas no decorrer das atividades desenvolvidas em sala de aula.

No intuito de garantir o anonimato dos sujeitos participantes da pesquisa, os nomes foram substituídos por algarismos alfanuméricos, a saber: Estudante 1 (E1), Estudante 2 (E2), Estudante 3 (E3) e assim consecutivamente. As análises desses dados coletas visaram compreender a contribuição da intervenção pedagógica desenvolvida. As discussões desses resultados foram possíveis tendo suporte no referencial teórico anteriormente apresentado.

\section{Resultados e discussões}

Ao se trabalhar EA, procuramos primeiramente refletir sobre o tema, realizando leituras seguidas de socialização dos pontos considerados fundamentais e debate relacionando com a realidade local. Esse momento foi importante para que os estudantes se familiarizassem com o assunto (sustentabilidade ambiental).

Nesse sentido, foram oportunizadas leituras e estudos dirigidos, seguidos de socialização e debates sobre as ações sustentáveis possíveis na atualidade e o estabelecimento de políticas locais, de ações governamentais e não governamentais, de ações de iniciativa popular, e as lutas pela melhoria da qualidade de vida e defesa do bem comum que é o nosso meio ambiente.

A partir das discussões ocorridas em aula, pode-se observar a falta de clareza que os estudantes apresentavam sobre as questões ambientais. Os estudantes 
manifestavam-se como se surpresos e admirados com o arcabouço teórico estudado, o qual apresentou conceitos e características básicas sobre a sustentabilidade, bem como os principais problemas ambientais que dificultam que práticas sustentáveis sejam adotadas no cotidiano.

Foi verificado que o conceito de sustentabilidade não é recente, portanto essa discussão se arrasta por décadas e está cada vez mais necessária. Ela começou a ser defendida em 1973, na Conferência de Estocolmo. O conceito então apresentado partiu do princípio de que o atendimento às necessidades básicas das populações, no presente, não deve comprometer os padrões de vida das gerações futuras. Sendo assim, a utilização dos recursos deve ocorrer de acordo com a capacidade de reposição da natureza, sem agredir de forma violenta e irreparável os ecossistemas. Esse foi o entendimento da sala multisseriada: nossos hábitos de consumo não podem provocar prejuízos para as próximas gerações.

No Quadro 1 serão ilustrados alguns trechos da produção textual sobre o assunto, ocorrida em aula após o amplo debate sobre as leituras propostas.

Quadro 1 - Trechos dos textos produzidos pelos estudantes.

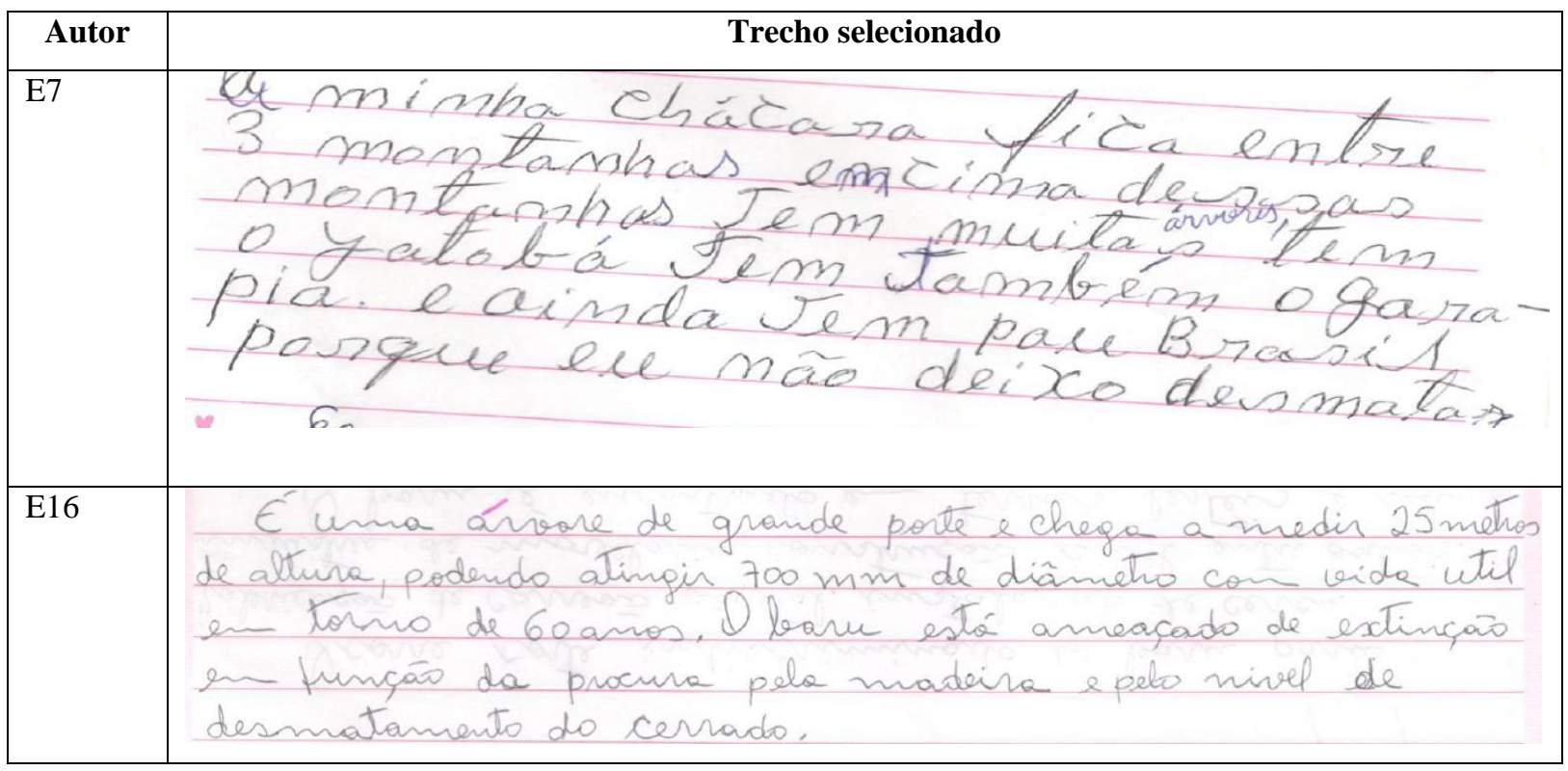




\begin{tabular}{|c|c|}
\hline E17 & 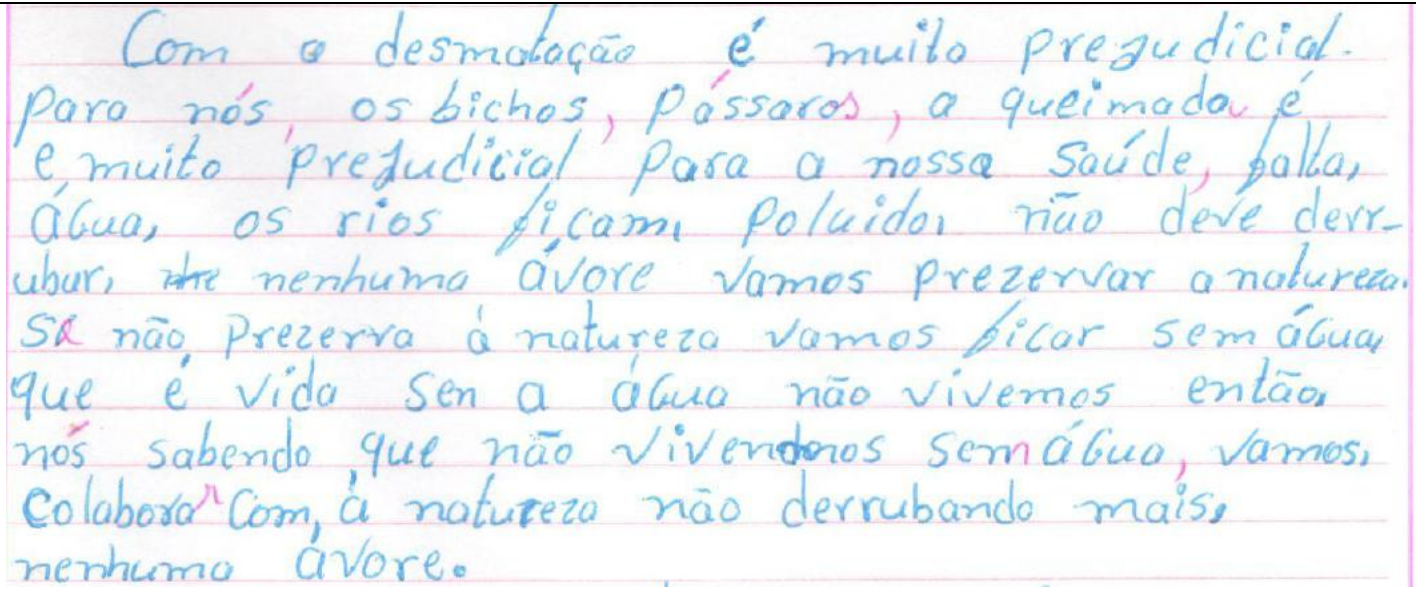 \\
\hline E22 & 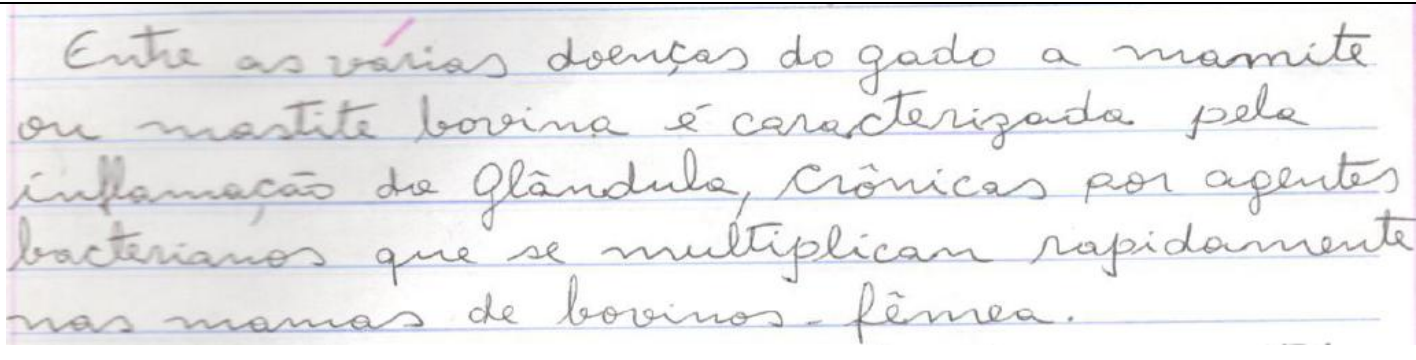 \\
\hline E24 & 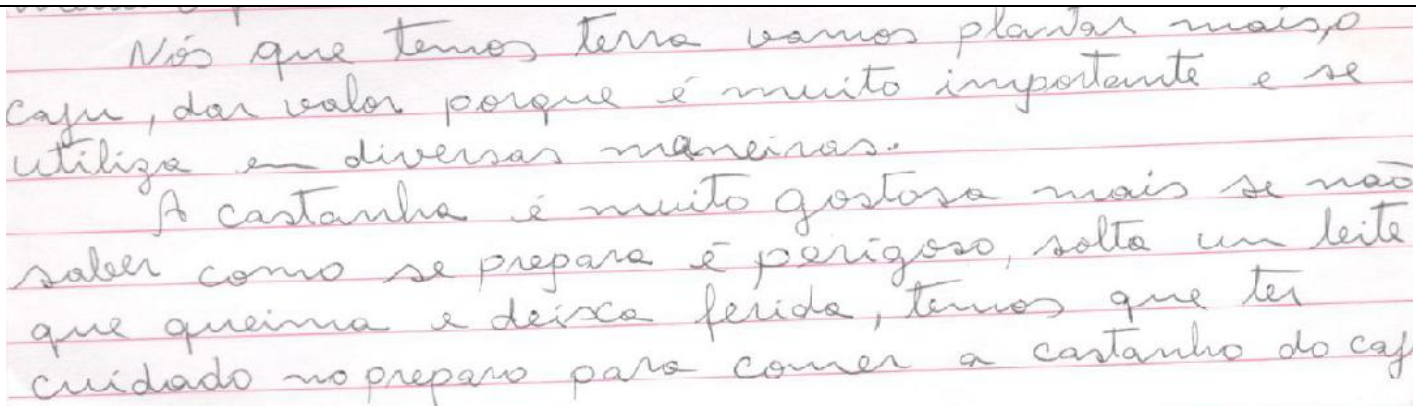 \\
\hline
\end{tabular}

Fonte: Elaborado pelos estudantes durante a atividade em aula (2016).

As produções textuais buscaram expressar essa reflexão sobre a importância de uma postura ambiental adequada, principalmente no que tange a exploração dos recursos naturais, o consumo e o fim dado ao lixo que produzimos. A análise desses textos permitiu conhecer aspectos próprios desse público, além do que pensam sobre as questões ambientais. Algumas peculiaridades desses sujeitos participantes foram trazidas para esse artigo.
Grande parte desses estudantes são produtores de leite, com isso criam uma pequena quantidade de gado. Para manter essa criação é necessário que se faça um desmatamento na propriedade para o plantio de pastos para criação de pasto. Contudo, embora agindo dessa forma, consideram ser possível conviver em harmonia com a natureza, pois desmatam o necessário e deixam em pé todas as árvores de médio e grande porte, que contribui para o descanso do gado em dias de muito 
sol. Ou seja, esse desmatamento não ocorre com a finalidade única de obtenção de lucros com a venda da madeira, ocorre diante de uma necessidade de subsistência.

Outra atividade que boa parte dos sujeitos realizam é o cultivo e coleta de frutas para extração de polpas. Em sua maioria, são frutas tropicais próprias para o cultivo na região, entre as quais estão o murici, o buriti, o caju, entre outras. Esse cultivo de certa forma contribui para o equilíbrio ambiental, pois dessa forma não desmatar as áreas em que são cultivadas essas frutas na região contribui significativamente com o meio.

Constatou-se que a extração da madeira com fins lucrativos também constitui a realidade local, tanto por informações contidas nos textos que produziram quanto em fotografias capturadas.

Frente a essa problemática, foi planejado e desenvolvido um projeto com o tema "Pau-brasil: uma árvore muito encontrada em diversas regiões do Brasil, em especial na mata atlântica". O fato de ainda ser encontrada essa espécie nativa na localidade, permitiu relacionar com aspectos históricos, econômicos e sociais, pois a exploração desse recurso natural contribuiu para diminuir e quase extinguir a espécie de nossas matas.

Por outro lado, também foram abordadas as diferentes maneiras de utilização dessa maneira nobre, tais como: construção de casas, cercas, objetos, pontes e, principalmente, móveis. Também foi discutido e identificado que a extração ilegal da madeira, não só a do pau-brasil, não é uma prática recorrente na região, mas não foi descartado o perigo dessa ação voltar a ser praticada, por isso a importância desse estudo. Outras atividades realizadas foram as palestras sobre o manejo e qualidade do leite e conservação de matas e áreas de florestas, além da que abordou o tema saúde e meio ambiente. Essas palestras estão ilustradas nas Figuras 1 e 2. 
Figura 1 - Palestra sobre qualidade do leite e conservação de áreas de florestas.

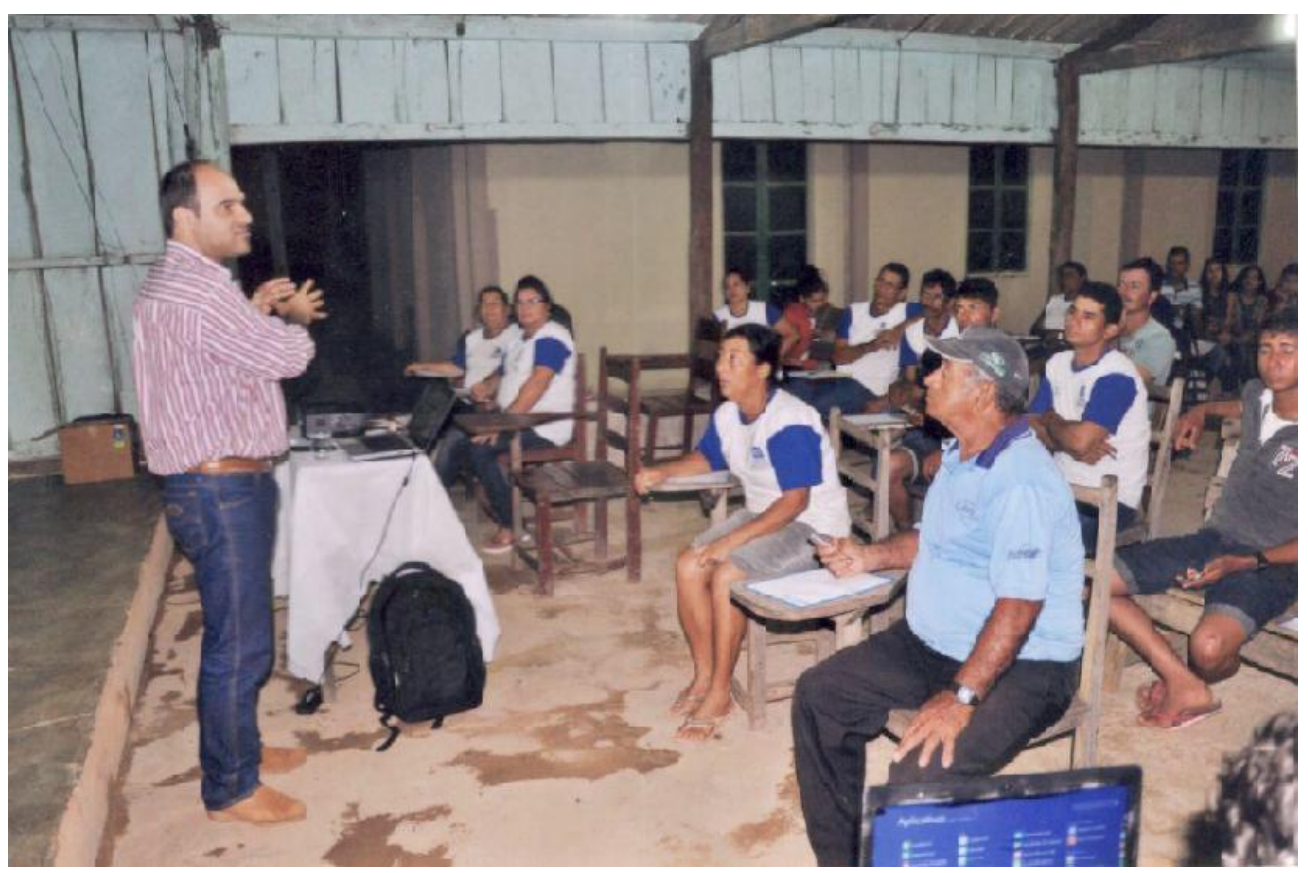

Fonte: Acervo pessoal de Ramos, E. D. (2016).

Essa palestra contribuiu para que os estudantes pudessem diagnosticar doenças no gado como a mastite, além de mostra a melhor forma de fazer o manejo do gado. Por meio da palestra, os estudantes puderam compreender melhor as questões ambientais e valorizar as riquezas locais, como a mata e a vegetação local, consideradas áreas de cerrado, considerado um dos biomas ameaçados em extinção.

Quando abordada a ação do homem sobre as florestas, foram citadas a escassez de algumas árvores tais como o pau-brasil, árvore nativa da mata atlântica, mas que embora encontrava-se muito na região local, assim como o pau-brasil, foram apontadas algumas outras árvores que estão ameaçadas, no caso Ipê-Roxo e Baru, pois é alto o índice de sua extração devido serem utilizadas no mercado para confeccionar móveis entre outros. 
Figura 2 - Palestra com o agente de saúde da comunidade local.

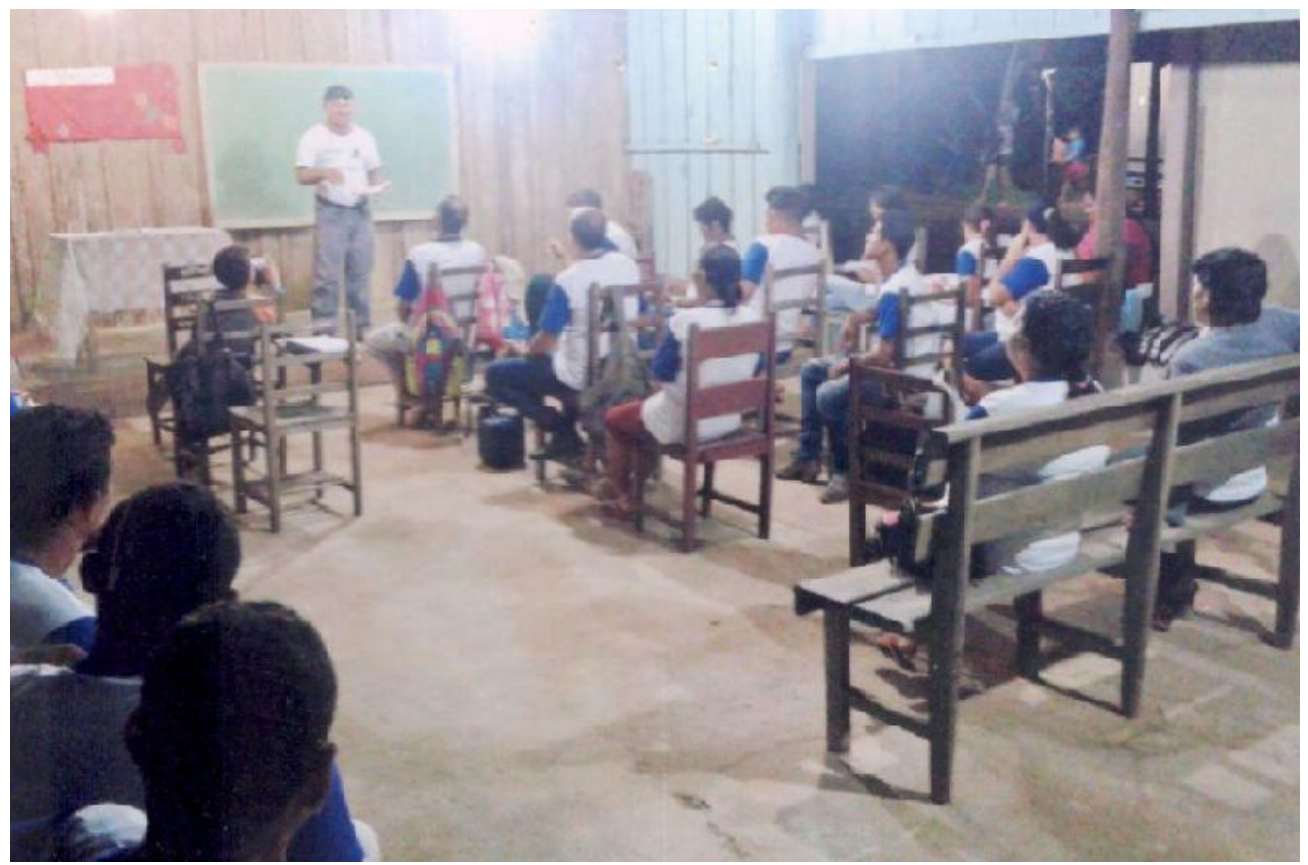

Fonte: Acervo pessoal de Ramos, E. D. (2016).

Nesse momento da intervenção pedagógica buscou-se orientar os estudantes por meio de palestras sobre as relações existentes entre o homem e o meio ambiente prática da sustentabilidade, pois, a partir de estudos realizados com estudantes em sala de aula. Buscou-se então sistematizar os conhecimentos construídos no decorrer das aulas, de maneira a levar esses saberes para suas práticas diárias, a exemplo do que ocorreu nos estudos de Leão (2014). A todo momento os estudantes se mostraram muito interessados, pois viram ali a oportunidade de crescer economicamente mais de maneira sustentável, buscando sempre uma melhor relação com o meio ambiente.
Após a realização dos estudos, os estudantes se mostraram bastantes ativos em rever algumas ações em relação as suas propriedades. Essas ações, além de promover a EA, permitiram superar as dificuldades enfrentadas pelas escolas do campo quanto aos recursos materiais, de estrutura física e de acesso às tecnologias, uma vez que a contextualização e os recursos disponíveis na localidade foram amplamente explorados no estudo (Silva \& Leão, 2017).

A produção da imagem por meio da fotografia foi outra atividade que teve boa participação dos estudantes. As Figuras 3, 4 e 5 ilustram a interação dos estudantes com o meio ambiente e as ações que já estão realizando a partir da realização desse estudo. 
Ramos, E. D., \& Leão, M. F. (2019). Sensibilização ambiental de estudantes da EJA de uma sala multisseriada no Projeto de Assentamento Porto Esperança em Confresa-MT...

Figura 3 - Criação de gado como prática econômica recorrente na região.

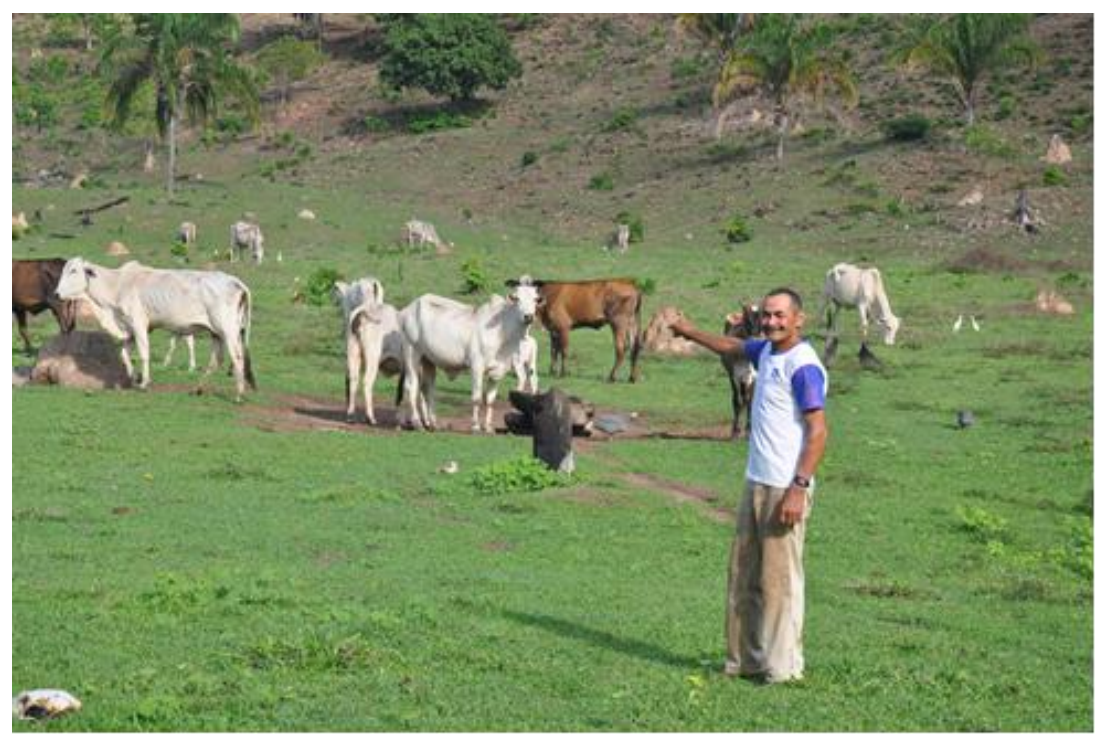

Fonte: Acervo pessoal do Estudante 1 (2016).

A Figura 3 mostra um estudante que

é criador de gado leiteiro que buscou reflorestar algumas áreas de pasto com árvores nativas para também amenizar a área de calor ocupada pelo gado. O mesmo buscou mostrar a prática adotada com seu rebanho e o desenvolvimento sustentável, uma iniciativa após ter participado da palestra sobre manejo.

Figura 4 - Preservação de lagos como maneira de garantir o equilíbrio térmico.

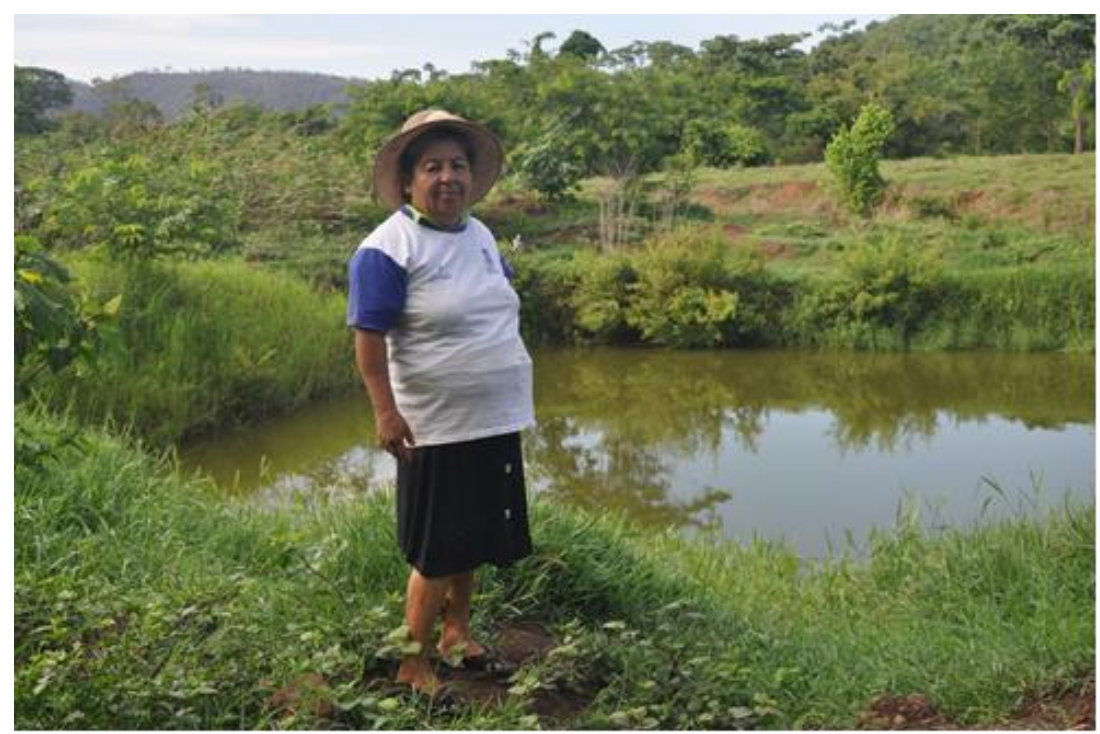

Fonte: Acervo pessoal da Estudante 3 (2016). 
Dessa maneira buscou-se entender a importância da preservação das margens de córregos e rios, protegendo-os de erosão causadas por águas das chuvas ou bebedouros de gado. Outra atividade em questão foi a criação de peixes em tanques, onde nas palestras buscou-se sintetizar e orientar meios de como fazer essa atividade de maneira sustentável e sem agredir o meio ambiente.

Sendo assim, sempre buscando priorizar a importância de saber como lidar com uma economia sustentável de forma solidária com o meio ambiente, cuidando assim das margens de áreas alagadas, pois com o tempo poderá secar com a agressividade do homem com o meio, uma vez que as preservações desses ambientes servem para além de contribuir para a melhoria do clima ainda podem ser vistas como um meio sustentável (Sato, 2004).

Isso mostra que a EA está além de ser um processo de mudança e formação de valores. Portanto, o preparo para o exercício da cidadania, constitui-se em um conjunto de ideias contrárias às ideias prevalecentes no sistema social atual. É uma luta a favor de novas ideias e valores éticos, em que deve prevalecer a melhoria da qualidade de vida para todos. Os aspectos mencionados são básicos para a superação do modelo tradicional de educação por meio da construção de uma nova escola.

Figura 5 - Criação de suínos como fonte de renda.

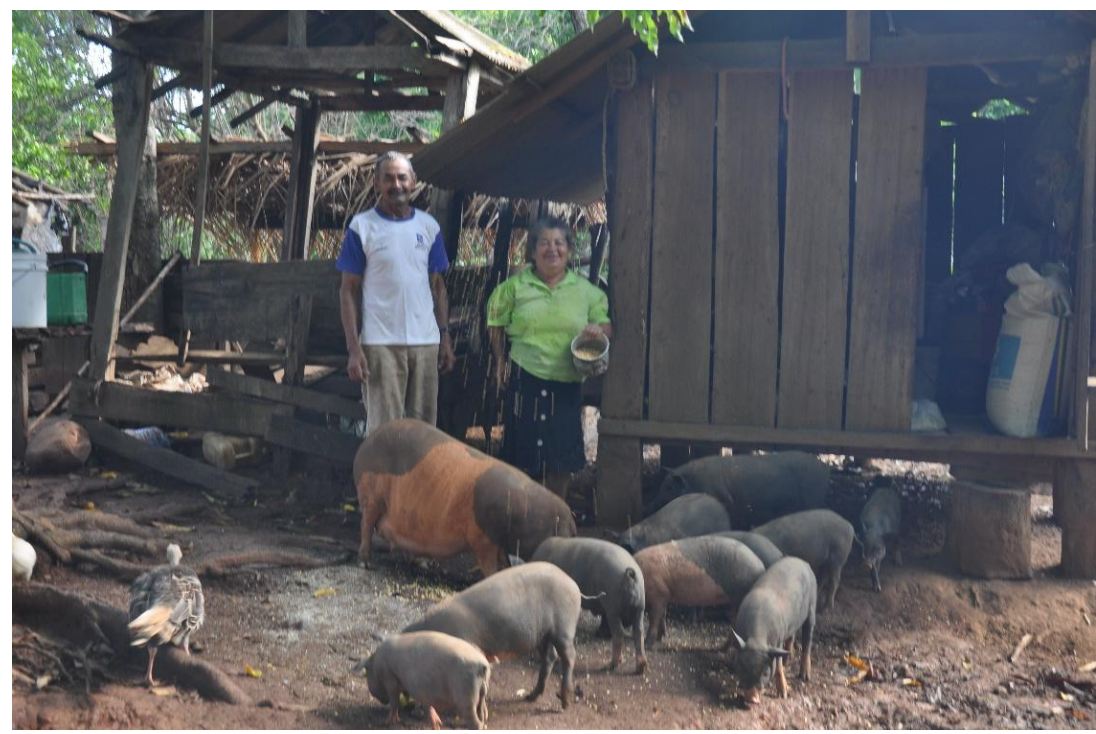

Fonte: Acervo pessoal do Estudante 13 (2016).

De maneira geral, essas atividades foram propostas no intuito de favorecer a interdisciplinaridade, cujo tema gerador possibilitou trabalhar de maneira a buscar a 
reflexão crítica, as discussões e argumentações em grupo e a reelaboração de conceitos. A proposta foi inserir discussões sobre o conceito de cidadania que está relacionado com preservação ambiental e sustentabilidade, a exemplo do que desenvolveu Fajardo (2003), o que pode levar os estudantes a assumirem uma postura adequada frente ao meio ambiente e tornarem-se participantes ativos na sociedade, pela preservação de toda a vida e pelo sentimento de responsabilidade pelo futuro comum do planeta Terra e da humanidade.

Ao se trabalhar EA em sala de aula, buscou-se o desenvolvimento do espírito crítico do estudante, onde o mesmo fosse capaz de favorecer a sua criatividade, o que corrobora o pensamento de Leff (2000). Além disso, a prática pedagógica adotou uma dinâmica de ensino que favoreceu não só o descobrimento, mas também as potencialidades do trabalho individual de cada estudante, sobretudo, as que se refere ao trabalho coletivo.

Conforme indicado pelos documentos oficiais, aconselha-se que a EA seja desenvolvida em todas as escolas como uma atividade transversal e intencional, pois suas ações refletirão na prática social dos envolvidos, além de contribuir para o desenvolvimento pessoal no que tange a relação com a natureza e com as outras pessoas (Brasil, 2012).

\section{Considerações finais}

O presente estudo oportunizou aos estudantes envolvidos e extensivamente a comunidade escolar e a sociedade local, momentos de reflexão, discussão, pesquisas e ações práticas que proporcionaram a sensibilização sobre a problemática ambiental e a busca por hábitos sustentáveis. O objetivo da intervenção pedagógica, anteriormente exposto, foi alcançado, uma vez que buscou abordar não somente os conteúdos e temas da disciplina de ciências naturais sobre o meio ambiente, mas de forma holística, integrando dados históricos, geográficos, econômicos e culturais.

A metodologia que foi desenvolvida, fez com que os estudantes dessa sala multisseriada da EJA buscassem superar sua visão simplista inicial atingindo uma visão crítica, buscando assim a transformação do contexto vivido, pois propiciou a associação com temas e assuntos do cotidiano. As discussões se deram principalmente quanto às mudanças de hábitos no cotidiano dos estudantes, enfatizando sempre a motivação para despertar e desenvolver atitudes de cidadãos conscientes e críticos. 
Os resultados obtidos nesse estudo indicam que a interdisciplinaridade pode ser trabalhada de forma prazerosa pelos estudantes da EJA do Ensino Médio, e que discutir o tema sustentabilidade ambiental auxilia na construção de valores que propiciem uma boa relação entre o homem e natureza. Portanto, verificou-se a necessidade de a escola desempenhar seu papel de agente promotora de reflexões e mudanças, que as ações não precisam necessariamente serem extensas ou complexas, mas sim que sejam possíveis de ser exequíveis, no sentido de provocar e estimular a necessidade de mudanças.

\section{Referências}

Andreola, B. (2000). Interdisciplinaridade na obra de Freire: uma Pedagogia da simbiogênese e da solidariedade. In Streck, D. R. (Org.). Paulo Freire: ética, utopia e educação (pp. p. 67-94). 3.ed. Petrópolis: Vozes.

Arroyo, M. (2006). Formação de Educadores de Jovens e Adultos. Belo Horizonte: Autêntica. SECAD/UNESCO.

Brasil. (2006). Caderno Trabalhando com a educação de Jovens e Adultos. Brasília: Ministério da Educação.

Brasil. (1988). Constituição: República Federativa do Brasil. Brasília: Senado Federal.

Brasil. (1996). Lei n. 9.394, de 20 de dezembro de 1996. Estabelece as diretrizes e bases da educação nacional. Brasília: Palácio do Planalto.
Brasil. (2012). Resolução n. 2, de 15 de junho de 2012. Estabelece as Diretrizes Curriculares Nacionais para a Educação Ambiental. D.O.U. no. 116, seção 1, p. 70, 18 jun. 2012. Brasília: Diário Oficial da União.

Freire, P. (2001). Pedagogia do oprimido. (31 ed). Rio de Janeiro: Paz e Terra.

Freire, P. (2005). A educação na cidade. (6 ed). São Paulo: Cortez.

Fajardo, E. (2003). Ecologia e cidadania: se cada um fizer a sua parte. Rio de Janeiro: Ed. Senac Nacional.

Gil, A. C. (2010). Como Elaborar Projeto de Pesquisa. (5 ed). São Paulo: Atlas.

Leão, M. F. (2014). Ensinar Química por meio de alimentos: possibilidades de promover Alfabetização Científica na Educação de Jovens e Adultos (Dissertação de Mestrado). Centro Universitário UNIVATES, Lajeado.

Leff, E. (200). Saber Ambiental: sustentabilidade, racionalidade, complexidade, poder. Petrópolis: Vozes.

Melo, J. R., \& Rotta, J. C. G. (2010). Concepção de ciência e cientista entre estudantes do ensino fundamental. In Anais $X V$ Encontro Nacional de Ensino de Química (XV ENEQ). Brasília: Sociedade Brasileira de Química

Santos, S. F., \& Leão, M. F. (2017). Uso de objetos educacionais digitais para ensinar sistemas do corpo humano em uma escola do campo. Revista Brasileira de Educação do Campo, 2(3), 861-880. Doi: https://doi.org/10.20873/uft.2525$\underline{4863.2017 \mathrm{v} 2 \mathrm{n} 3 \mathrm{p} 861}$

Sato, M. T. (2004). Educação Ambiental. In Selbach, S. (Org.). Arte e didática (pp. 36-45). Coleção Como Bem 
Ensinar/coordenação Celso Antunes. Petrópolis, RJ: Vozes.

Sauvé, L. (2005). Uma cartografia das correntes em educação ambiental. In Sato, M., \& Carvalho, I. (Orgs.). Educação ambiental: pesquisas e desafios (pp. 1744). Porto Alegre: Artmed.

Soares, L. (2008). Avanços e Desafios na formação do Educador de Jovens $e$ Adultos adulto. Formação de educadores de jovens e adultos/organizado por Margarida Machado - Brasília: Secad/MEC/UNESCO.

Unesco. (2004). Educação de Jovens e Adultos: Uma memória contemporânea, 1996-2004. Coleção educação para todos. Brasília: UNESCO/MEC.

\section{Informações do artigo / Article Information}

Recebido em : 31/12/2017

Aprovado em: $26 / 04 / 2018$

Publicado em: 18/12/2019

Received on December 31th, 2017

Accepted on April 26th, 2018

Published on December, 18th, 2019

Contribuições no artigo: Os autores foram responsáveis por todas as etapas e resultados da pesquisa, a saber: elaboração, análise e interpretação dos dados; escrita e revisão do conteúdo do manuscrito e; aprovação da versão final publicada.

Author Contributions: The author were responsible for the designing, delineating, analyzing and interpreting the data, production of the manuscript, critical revision of the content and approval of the final version published.

Conflitos de interesse: Os autores declararam não haver nenhum conflito de interesse referente a este artigo.

Conflict of Interest: None reported.

Orcid

Elaine Darc Ramos

(iD) http://orcid.org/0000-0003-2375-473X

Marcelo Franco Leão

(iD) http://orcid.org/0000-0002-9184-916X

Como citar este artigo / How to cite this article

APA

Ramos, E. D., \& Leão, M. F. (2019). Sensibilização ambiental de estudantes da EJA de uma sala multisseriada no Projeto de Assentamento Porto Esperança em Confresa-MT. Rev. Bras. Educ. Camp., 4, e4860. DOI: http://dx.doi.org/10.20873/uft.rbec.e4860

ABNT

RAMOS, E. D.; LEÃO, M. F. Sensibilização ambiental de estudantes da EJA de uma sala multisseriada no Projeto de Assentamento Porto Esperança em Confresa-MT. Rev. Bras. Educ. Camp., Tocantinópolis, v. 4, e4860, 2019. DOI: http://dx.doi.org/10.20873/uft.rbec.e4860 